\title{
MacINTYRE PARA TEÓLOGOS
}

\author{
Maclntyre to Theologians
}

Elton Vitoriano Ribeiro

FAJE

Resumo: O pensamento filosófico de Alasdair Maclntyre tem influenciado um grande número de intelectuais das mais variadas áreas do conhecimento humano. Sociologia, economia, história, medicina e teologia, são alguns exemplos. Neste artigo, abordarei a questão narrativa no pensamento de Maclntyre e sua relevância para questões teológicas contemporâneas. Primeiro, perguntando pelas relações entre filosofia e teologia. Depois, aprofundando a questão da narrativa na teologia e no pensamento de Maclntyre. Finalmente, apontando caminhos, a partir do pensamento de Maclntyre, para o pensar teológico face aos desafios contemporâneos.

Palavras-chave: Narrativa, filosofia, teologia, Maclntyre.

Abstract: The philosophical thought of Alasdair Maclntyre has influenced a larger number of intellectuals from the most varied fields of human knowledge. Sociology, economics, medicine and theology, are some examples. In this article, I will address the question of narrative in the thought of Macintyre and its relevance for contemporary theological questions. Firstly, considering the relations between philosophy and theology. Then, deepening the question of narrative in theology and in the thought of Maclntyre. Finally, parting from the thought of Maclntyre, pointing to ways of theological thinking to face contemporary challenges.

Keywords: Narrative, philosophy, theology, Maclntyre

O pensamento filosófico de Alasdair Maclntyre tem influenciado um grande número de intelectuais das mais variadas áreas do conhecimento humano. Sociologia, administração, política, economia, história, medicina e teologia, são alguns exemplos. Neste artigo, pretendo abordar a questão da compreensão narrativa da vida humana presente no pensamento de Maclntyre e sua relevância para algumas questões importantes, que se apresentam como tarefas, para a reflexão teológica cristã. Farei 
isso primeiro, perguntando pelas relações entre filosofia e teologia. Depois, apresentando a questão da narrativa na teologia cristã, e aprofundando a mesma questão no pensamento de Maclntyre. Finalmente, apontando caminhos, a partir do pensamento de Maclntyre, para a reflexão teológica frente aos desafios contemporâneos.

\section{A Filosofia, amiga também da teologia?}

A discussão acerca das relações entre filosofia e teologia cristã tem encontrado pontos importantes para a reflexão a partir do pensamento de Alasdair Maclntyre. Por um lado, vários teólogos, especialmente moralistas e teólogos preocupados com os caminhos da sociedade secularizada, encontram nos textos de MacIntyre pertinentes provocações ao pensar teológico. O próprio Maclntyre também vem ao longo dos anos se preocupando com questões que são relevantes aos teólogos como, por exemplo, Deus e a tradição católica de reflexão presente em documentos do magistério eclesial da igreja católica (MACINTYRE, 2009). Por outro lado, a teologia cristã sempre defendeu e valorizou o pensar filosófico como uma necessidade intrínseca do pensar teológico (RIBEIRO, 2001, p.273-276). A parte algumas correntes teológicas que desejaram substituir a filosófica pela sociologia, a antropologia, ou a psicologia, entre outras ciências; o magistério da igreja católica, por exemplo, possui entre seus documentos um texto altamente elogioso à filosofia intitulado "Fides et Ratio: sobre as relações entre fé e razão" (JOÃO PAULO II, 1998). Importante dizer, texto comentado várias vezes por MacIntyre (MACINTYRE, 2009, p.165-172).

Uma das preocupações da teologia, que a conduz à valorização da filosofia, é a de sempre manter-se atenta contra os extremos do fideísmo e do fundamentalismo. Extremos matam o pensar teológico. A filosofia, por sua postura crítica e questionadora, ajuda a teologia a manter-se sempre alerta diante do pensamento rápido e fácil que inunda nossos meios de comunicação. A filosofia adentra-se nas perguntas e questões fundamentais que marcam a existência humana. É destas 
questões que, à sua maneira, a teologia também irá enfrentar: Quem sou eu? O que devo fazer? Como viver e construir uma sociedade justa? O que posso esperar? O que é o mal? Deus existe? Qual o sentido da vida humana no mundo histórico? Estas e outras perguntas tocam o cerne da existência humana no mundo, do sentido desta mesma existência e de suas consequências para nossas vidas históricas.

Vários teólogos, inspirados pela filosofia de Maclntyre, enriqueceram seu pensar teológico. Os dois mais conhecidos, e que explicitamente falam desta dívida são Stanley Hauverwas (HAUVERWAS, 2014) e John Milbank (MILBANK, 1995). Outros teólogos moralistas como James F. Keenan (KEENAN, 2000), Otto Hermann Pesch (PESCH, 1987), Martin McKeever (MCKEEVER, 2005) e Terence Kennedy (KENNEDY, 1991) são influenciados por Maclntyre em temas específicos como a importância das virtudes para a vida humana, o lugar das tradições na autocompreensão das religiões e a crítica a uma postura iluminista e emotivista da sociedade contemporânea. Os casos de Hauverwas e Milbank são os mais interessantes para meu propósito aqui. Hauverwas é, como Maclntyre, um crítico dos postulados iluministas e emotivista da cultura moderna. Ele propõe, para a revalorização da experiência cristã, um compromisso com a não violência, com a justiça, com o cuidado aos pobres. Isto será possível com a recuperação das virtudes desde uma perspectiva pacifista. Milbank é um caso curioso. Ele diz na introdução de um de seus principais livros, "Teologia $e$ Teoria Social", que existe em seu pensar uma "voz macintyriana", e que a real perspectiva do livro vem a ser a da virtude. Por um lado, esta perspectiva é despertada pelo diálogo fecundo com Maclntyre. Por outro lado, ele diz estar também em constante disputa com Maclntyre porque para ele a virtude cristã, diferentemente do que pensa Maclntyre, segundo Milbank, é uma posição superior e contrária tanto à antiguidade como à modernidade. Importante lembrar ainda da importância, tanto para Milbank quanto para MacIntyre, da fecundidade da reflexão sociológica para a filosofia e a teologia. 
Dentro desta discussão entre filosofia e teologia, quero ressaltar que um tema importante para Maclntyre e que ainda não teve recepção por parte dos teólogos é o tema da narratividade da vida humana. Curioso notar que a maioria dos teólogos preocupados com a teologia narrativa citam frequentemente Ricoeur (RICOEUR, 2014, p.167-176) e Taylor (TAYLOR, 1997, p.71); ambos, importante dizer, em constante diálogo com Maclntyre nesta questão. Ora, como a teologia nos últimos anos tem se preocupado com a dimensão narrativa dos relatos bíblicos e da própria experiência de fé, a reflexão de Maclntyre pode despertar uma maior atenção a dimensão narrativa da vida humana e seu lugar na busca humana, dentro de uma tradição, por uma vida com sentido.

\section{A importância da reflexão filosófica sobre a narratividade para a teologia}

Nas últimas décadas a reflexão teológica cristã tem se voltado com interesse para a questão da narratividade. O interesse foi suscitado, especialmente, pelo aprofundamento da reflexão acerca do lugar da bíblia no pensamento teológico e pelo carácter histórico da fé cristã. Na medida mesma em que a teologia tomava mais consciência da importância fundamental da bíblia para a reflexão teológica, a preocupação pela forma como o texto bíblico foi narrado, e pela incidência destas narrativas na vida das pessoas que leem estes textos; foi-se tornando mais presente nos discursos teológicos, doutrinais e catequéticos o discurso narrativo. Por exemplo, ganhou grande destaque no universo teológico contemporâneo a reflexão de Gerard Von Rad (RAD, 1973) sobre a forma narrativa da confissão de fé, a preocupação de Ernest Käsemann (KASEMANN, 1978) sobre o valor teológico da formação narrativa da vida de Jesus e os estudos de Eberhard Jüngel (JUNGEL, 1978) sobre a linguagem narrativa das parábolas de Jesus. Mais recentemente, teólogos importantes como Claude Geffré (GEFFRÉ, 1989) e Adolphe Gesché (GESCHÉ, 1994) se preocuparam com o lugar da narrativa na experiência de fé do crente. Assim, tanto a pesquisa teológica sobre a compreensão da salvação cristã como história vivida e narrada, quanto à 
reflexão exegética sobre a construção narrativa dos escritos bíblicos, tornaram-se lugar comum na formação de todo teólogo cristão. É curioso notar como, por exemplo, a bíblia nos apresenta esta realidade humana da narrativa. Na bíblia temos uma quantidade enorme de gêneros literários: mitos, tradições populares, crônicas, biografias exemplares, biografias romanceadas, genealogias, narrativas histórias, narrativas sapienciais, etc. Para a teologia, o caso paradigmático é a própria vida de Jesus Cristo narrada por quatro evangelhos adotados canonicamente pela comunidade cristã (PALACIO, 1997).

Filosoficamente, o problema fundamental que guia esta guinada narrativa na teologia é o fato de que os seres humanos, para falar como Maclntyre, são animais que contam histórias. As narrativas fazem parte da vida dos seres humanos e, podemos dizer, organizam nossa forma de ser no mundo como seres que se compreendem por meio de narrativas. Nas palavras de Maclntyre: "Sonhamos em formas de narrativas, devaneamos em narrativas, recordamos, duvidamos, planejamos, reconsideramos, criticamos, inventamos, mexericamos, aprendemos, odiamos e amamos por meio de narrativas" (MACINTYRE, 2001, p.355). Narrar a vida é, pra nós humanos, resgatar o tempo passado ultrapassando a mera crônica dos fatos, mas articulando-os segundo uma necessidade de sentido. É humanizar o vivido, desdobrando uma identidade que nos ajuda a compreender o presente e projetar o futuro. A narrativa é tão importante que ela nos apresenta ao mesmo tempo a irreversibilidade do passado, nos dizendo que ele poderia ter sido de outro modo, e nos lança ao futuro na constante continuidade da existência que devemos construir narrativamente. Narrar é dar testemunho de que a identidade humana é uma identidade aberta, por isso mesmo livre, que se apresenta, narrativamente, diante de nós como uma forma possível de existência.

De tudo o que foi apresentado acima, a minha intuição neste texto é a de a reflexão de Maclntyre acerca da importância da narratividade na vida humana pode ser muito útil para a teologia cristã. Especialmente, quando a teologia se preocupa em 
compreender a fé como um encontro, que gera uma experiência, dentro de uma determinada tradição. Experiência esta que tem uma finalidade prática, ética, de gerar um ethos na comunidade e uma disposição no indivíduo que produza uma nova compreensão de si mesmo, mais aprofundada e mais abrangente. Produza, para falar como Ricoeur, uma conversão e uma decisão na vida concreta (RICOEUR, 2006, p. 225232). É neste momento que a filosofia de Maclntyre pode iluminar o caráter narrativo da existência humana no mundo.

\title{
3. Aprofundando a questão narrativa
}

Para Maclntyre a vida humana não pode ser reduzida a simples momentos esporádicos, fragmentados, isolados uns dos outros. A vida humana possui uma unidade narrativa com início, meio e fim. Nascimento, vida e morte. É neste percurso que minha vida é construída narrativamente. Charles Taylor, inspirado em Maclntyre, elucida bem este percurso quando diz:

\begin{abstract}
Minha vida tem sempre esse grau de compreensão narrativa. Compreendo minha ação presente na forma de um e então: havia A (o que sou), então faço $B$ (o que projeto me tornar). Porém, a narrativa precisa desempenhar um papel maior que a mera estruturação de meu presente. $O$ que sou tem de ser entendido como aquilo que me tornei. (...) Só podemos dar uma resposta a esse tipo de pergunta verificando como esses momentos se enquadram na vida circundante, isto é, que papel desempenham numa narrativa dessa vida (TAYLOR, 1997, p.71).
\end{abstract}

A afirmação de Taylor é apresentada de forma condensada por Maclntyre quando afirma que: "O homem é, em suas ações e práticas, bem como em suas ficções, essencialmente um animal contador de histórias" (MACINTYRE, 2001, p.363). Nestas histórias é revelado um eu inseparável das relações sociais, dos papeis sociais e das tradições que compõem o pano de fundo, o horizonte de interpretação e compreensão da vida humana. Nas narrativas, as ações humanas, como na vida, são interpretadas entendendo cada evento particular dentro de um conjunto maior de narrativas, de histórias dos indivíduos envolvidos, de contextos que dão sentido. Por isso, para MacIntyre, a unidade da vida humana consiste na unidade de uma narrativa. 
Como atores e como autores nós vivemos narrativamente nossas vidas. E estas narrações se entrelaçam com as narrações das vidas das outras pessoas como as quais convivemos. Na verdade, cada pessoa é o personagem principal de sua vida, sua narrativa, seu drama; mas personagem secundário nos dramas, nas narrativas, nas vidas das outras pessoas. Além disto, as nossas vidas, nossas narrativas, nós as vivemos em um determinando contexto social que não escolhemos. Afirma Maclntyre: "subimos em um palco que não criamos" (MACINTYRE, 2001, p.359). Este palco é importante na medida mesma em que nos situa temporal e espacialmente. Eles encarnam nossas ações e nossas práticas. Como afirma Maclntyre: "Não podemos caracterizar o comportamento independentemente das intenções, e não podemos caracterizar as intenções independente dos cenários que tornam essas intenções inteligíveis, tanto para os próprios agentes quanto para outras pessoas" (MACINTYRE, 2001, p.347).

Importante ressaltar que cada narrativa, de pessoas, comunidades, instituições e tradições, é marcada pela imprevisibilidade. Não conhecemos o futuro, mas sempre o projetamos em determinada direção. E neste projetar, aspiramos à verdade. Para MacIntyre, somos contadores de histórias que aspiram à verdade. Esta nossa aspiração, esse nosso desejo de, para falar como Ricoeur, "estar na verdade" (RICOEUR, 1968, p.58) marca profundamente nossas narrativas. Como sabemos, o estudo filosófico sobre a questão da verdade encontra atualmente uma diversidade muito grande de teorias da verdade (KIRKHAN, 2003). Um trabalho desta dimensão no pensamento de Maclntyre merece um aprofundamento. No entanto, para a intenção de minha argumentação aqui, entendo que a compreensão da verdade que marca nossas narrativas apresenta uma tríplice dimensão (RIBEIRO, 2011a). Em nossas narrativas a verdade é da ordem do testemunho, ela é histórica e nasce do consenso. Por exemplo, para a teologia, ela nasce como a fé cristã do testemunho daqueles que viveram com Jesus de Nazaré, está encarnada na história de uma tradição cristã, e é fruto de um processo argumentativo intersubjetivo de consenso. Por isso, uma 
aproximação à compreensão da verdade na narrativa filosófica com a narrativa teológica é extremamente frutífera. Frutífera porque uma interpretação hermenêutica e narrativa da verdade na religião tem sempre muito presente nossa existência humana no mundo. Existência de seres sempre em projeto, sempre em devir. Seres que buscam um sentido para suas vidas. Busca que não pode ser compreendida deslocada da linguagem, e é acessível num processo de interpretação hermenêutico. Processo hermenêutico que exige uma compreensão da vida humana de forma narrativa. Processo que se desdobrará a partir de testemunhos, que acontecem historicamente, e que são expressão do consenso comunitário.

Também, nesta narrativa que estrutura minha vida, sou responsável pelas minhas ações e pelas experiências que compõem minha vida. Eu posso ser convocado a dar explicações sobre o que fiz ou o que aconteceu em determinado momento de minha vida. A narrativa é minha, construída com outros no mundo, mas minha. Para Maclntyre: "Não sou apenas responsável, sou alguém que pode sempre pedir explicação aos outros, que pode questionar os outros" (MACINTYRE, 2001, p.366). Estas responsabilidades éticas de minhas ações, de minhas narrativas, compõem e estruturam minha vida como um relato de busca. Como bem observou Taylor, inspirado por Maclntyre:

Logo, encontrar sentido em minha ação presente, quando não estamos diante de questões triviais como onde estarei dentro de cinco minutos, mas com uma interrogação acerca de minha posição com respeito ao bem, requer uma compreensão narrativa de minha vida, um sentido sobre o que me tornei que só pode ser conferido pela história. E, ao projetar minha vida para a frente e endossar o rumo atual ou dar-lhe um novo, projeto uma história futura, não só um estado futuro momentâneo, mas uma direção a ser seguida por toda a minha vida vindoura. Esse sentido de que minha vida está dirigida para aquilo que ainda não sou é o que Alasdair Maclntyre capta em sua noção, (...), de que a vida é vista como uma busca (TAYLOR, 1997, p.72).

Como bem esclarece Taylor, para MacIntyre, o que possibilita a unidade da vida humana é que ela consiste, basicamente, num relato de busca. A busca se 
configura como um caminho a ser seguido. Não é um sistema já conhecido de início. Claro, é uma busca dentro de uma determinada tradição, de um determinado sistema social de práticas, crenças e valores. Mas, "é no decorrer desta busca, e somente ao se deparar e superar os diversos males, perigos, tentações e tensões que proporcionam à jornada de busca seus episódios e incidentes, que finalmente se pode compreender a meta da busca. A busca é sempre uma educação, quanto ao caráter do que se procura e de autoconhecimento" (MACINTYRE, 2001, p.368).

Ora, mas qual o télos, se é que existe um, desta busca? Para onde ela aponta? Para a vida humana, diz MacIntyre, este télos será a busca de uma vida boa para o ser humano. Cada tradição dará uma direção e virtudes próprias que apontam nesta direção. Assim, "a vida virtuosa para o homem é a vida virtuosa passada na procura da vida boa para o homem, e as virtudes necessárias para a procura são as que nos capacitam a entender o que mais e mais é a vida boa para o homem". Curioso notar a direção que a teologia cristã apresenta para esta perspectiva. Para a teologia cristã, o télos da busca da vida boa do cristão pode ser compreendido como o Reinando de Deus (RIBEIRO, 2011, p.285-292). Esta expressão, Reinado de Deus, importante para a teologia pode ser compreendida aqui como o anúncio do conteúdo essencial da boa notícia dos cristãos narrada nos evangelhos. Com efeito, para os cristãos é com e na pessoa de Jesus Cristo que se torna presente o advento do Reinado de Deus. Depois, os discípulos de Jesus Cristo recebem dele a missão de continuar esse anuncio de Reinado e o fazem narrando a vida de Jesus Cristo que se torna paradigma, texto canônico, para a vida e as práticas de cada cristão. A narração da vida de Jesus configura a vida de cada cristão e, nas práticas e na tradição cristã, se encarna através das virtudes cristãs, especialmente da fé, da esperança e da caridade.

Assim, as virtudes próprias da experiência cristã são disposições que configuram a pessoa interiormente neste caminho para a vida boa que a tradição cristã apresenta. Este caminho, como repeti várias vezes, acontece dentro de um contexto histórico determinado. Contexto que, configurando-se a partir dos contextos 
anteriores e em diálogo com eles, forma a tradição cristã. E nesta tradição que cada cristão vai viver concretamente sua fé e as práticas decorrentes deste comprometimento. Maclntyre esclarece filosoficamente este processo afirmando: "Apelar para uma tradição significa insistir que só podemos identificar adequadamente nossos próprios compromissos e os dos outros nos conflitos argumentativos do presente se os situarmos dentro das histórias que os fizeram ser o que são" (MACINTYRE, 2008, p.24). Ou seja, são as narrativas construídas ao longo da história que constituem as tradições, que constituem as práticas e as virtudes; e que nos constituem enquanto membros de uma determinada tradição.

Sendo assim, é fácil perceber porque Maclntyre insiste que cada pessoa vive sua identidade moral no interior de uma comunidade, ou das várias comunidades das quais faz parte. É no interior de comunidades que encarna tradições que vivemos e discutimos constantemente acerca das nossas práticas, dos bens internos e externos às práticas, das virtudes, das histórias e da vida boa. Estas discussões, que muitas vezes são fontes de conflitos, encarnam nossos desejos de fazer de nossas vidas, narrativamente, a história de uma busca pela vida boa. Daí a excelente definição de Maclntyre sobre como devemos compreender, filosoficamente, uma tradição:

\footnotetext{
Uma tradição é uma argumentação, desenvolvida ao longo do tempo, na qual certos acordos fundamentais são definidos e redefinidos em termos de dois tipos de conflitos: os conflitos com os críticos e inimigos externos à tradição que rejeitam todos ou pelos menos partes essenciais dos acordos fundamentais, e os debates internos, interpretativos, através dos quais o significado e a razão dos acordos fundamentais são expressos e através de cujo progresso uma tradição é constituída (MACINTYRE, 2008, p. 23).
}

Por isso, para Maclntyre, uma tradição é sempre uma conjunção de uma determinada forma de vida e de histórias de conflitos. Por um lado, enquanto forma de vida, ela gera constantemente um debate interno sobre as virtudes, os bens e a vida boa. Por outro lado, enquanto história dos conflitos, ela argumenta que a forma atual é herdeira de uma série de narrativas conflitivas que ao longo do tempo geraram 
debates que transformaram a própria tradição. Não podemos nunca esquecer que as tradições vivas geram sempre este processo contínuo de transformação e reconfiguração interna. Por exemplo, os teólogos possuem na tradição da igreja católica com seus concílios, sínodos e debates, um excelente exemplo, como estudou Mckeever em suas análises sobre a evolução do ensinamento social da igreja católica (MCKEEVER, 2005). Assim, cada tradição é portadora de uma dinâmica interna de desenvolvimento.

Importante lembrar que para MacIntyre, cada tradição tem que enfrentar crises epistemológicas para sobreviver. Por crise epistemológica (MACINTYRE, 2006, p.3-23) entende-se um estado de dissolução das crenças e dos argumentos que historicamente tiveram relevância, força, para a formação da tradição. É um estado onde novas e diferentes interpretações começam a questionar o arcabouço argumentativo da tradição e faz com que os conflitos aumentem. É um estado onde:

\footnotetext{
Textos ou sentenças de autoridade podem ser revelados como suscetíveis de interpretações alternativas e incompatíveis, que prescrevem, talvez, ações alternativas e compatíveis (...). O enfrentamento de novas situações, que geram novas questões, pode revelar, nas práticas e crenças estabelecidas, uma falta de recursos para oferecer respostas a essas novas questões ou para justifica-las (MACINTYRE, 2008, p. 381).
}

Como reação a uma situação de crise, surge novas interpretações da própria tradição que a faz transformar-se constantemente. Conflitos, reformulação de argumentos, novos acordos e novas práticas são geradas. É a tradição viva se reconfigurando. Ao reconfigurar-se, ela encarna-se, como sempre, em estruturas institucionais que produzem documentos canônicos que dão forma e estabilidade para as novas práticas e interpretações. Daí, por exemplo, ser fácil compreender porque, ao longo da história foi surgindo uma diversidade enorme de teologias, ou melhor, de formas teológicas de se aproximar racionalmente do mistério da fé por meio de doutrinas, ritos, normas, liturgias e catequeses. Ainda, esse conflito tem também sua vertente externa no conflito com outras tradições. O conflito externo segue a mesma 
dinâmica na qual, ao longo da argumentação, descobre-se que os próprios padrões de argumentação podem não ter sido suficientes para resolver determinados problemas. Esta descoberta gera o reconhecimento da própria fraqueza, da incapacidade de se resolver os problemas adequadamente e leva a perceber as incoerências internas.

\section{Alguns caminhos para a reflexão teológica}

A partir da apresentação do pensamento de Maclntyre sobre a questão da narrativa, gostaria de propor algumas pistas para a reflexão teológica. Além das abordagens dos teólogos que apresentei anteriormente, e que apropriaram diversos elementos da filosofia de Maclntyre, a reflexão teológica pode ser enriquecida com a filosofia narrativa de Maclntyre em três direções: na compreensão do imaginário narrativo da religião, na abordagem mistagógica da catequese narrativa e no caráter narrativo da normatividade da teologia moral.

Um tema muito importante para a teologia é a influência da fé na constituição do imaginário social das sociedades contemporâneas (RIBEIRO, 2013). As mudanças sociais e culturais nos imaginários destas sociedades faz com que os imaginários sejam, cada vez mais, secularizados. A incidência na forma de viver e compreender a religião, as práticas religiosas e as próprias tradições se transformam rapidamente. As sociedades ocidentais, por exemplo, cada vez menos possuem elementos de um antigo imaginário social cristão que dominou por muito tempo a forma dos indivíduos ocidentais se compreenderem e narrarem suas vidas. Por exemplo, as histórias dos santos quase não possuem mais nenhuma influência na vida das pessoas, mesmo as que professam a fé cristã. Ora, como sabemos, o imaginário social é algo que vem muito antes que as teorias apareçam, com suas explicações, distinções e análises. 0 imaginário é o pano de fundo de nossas vidas, nosso horizonte de interpretação e compreensão do mundo. Este horizonte se constrói narrativamente. Na verdade, as pessoas dão sentido às próprias vidas e projetos existenciais por meio, não de conceitos racionalmente justificados, mas de narrações, de imagens, de práticas 
partilhadas pelas comunidades que vivem e pelos outros significativos com os quais convivem. Por isso, as mudanças culturais que efetivamente atingem a vida espiritual das pessoas, a vida de fé, e que são objetos de reflexão dos teólogos, possuem um caráter narrativo. As buscas de novas linguagens, as novas histórias que compõem nosso imaginário social, nossos desejos e projetos, são narrativamente constituídos. Uma boa história, narrada ou vivida, pode mudar a vida de uma pessoa. Temos aí uma bela questão para os teólogos: o ser humano vive sua fé narrativamente. A fé influencia e é influenciada pelo imaginário social que também se estrutura narrativamente. Como, então, compreender o ato de fé neste cenário?

Uma das preocupações fundamentais da teologia é a transmissão da tradição religiosa e a transmissão da fé às novas gerações (GOPEGUI, 2010). Este processo é conhecido como catequese. Por exemplo, no início do cristianismo, a catequese era basicamente a narrativa do acontecido com Jesus de Nazaré. A vida de Jesus era narrada para aqueles que desejavam seguir este novo caminho. Os primeiros relatos narrativos datam do ano 37 da era cristã. Curioso notar que na tradição cristã, a catequese nasce já com um caráter narrativo, fixado depois, canonicamente em quatro evangelhos, ou seja, quatro boas notícias. Mas todos os evangelhos com um fundo comum: narrar as palavras, os atos e as práticas de uma mesma pessoa, Jesus de Nazaré. Ao narrar, a catequese cristã torna-se mistagogia, quer dizer, caminho de aprofundamento do mistério da fé cristã numa determinada tradição. Ora, mergulhar na dimensão mistérica da fé cristã, fé que acontece na dinamicidade da vida, é sempre entrar num processo hermenêutico de interpretação da narração dos textos bíblicos. Fé que é vivida e celebrada em práticas, numa determinada tradição. Fundamentalmente, eis a tarefa da catequese e da teologia cristãs: interpretar a narração da experiência da misteriosa gratuidade de Deus na vida dos seres humanos assim como nós encontramos nos relatos bíblicos da tradição narrativa cristã.

A reflexão de Maclntyre sobre as virtudes foi a que mais influenciou a teologia moral, como narrei anteriormente. No entanto, outro aspecto importante é o da 
reflexão sobre o caráter narrativo da normatividade moral (RIBEIRO JÚNIOR, 2003). Ora, para a teologia moral, a moral cristã possui três dimensões. Uma dimensão revelacional, que explicita a maneira como os cristãos entendem a comunicação de Deus na pessoa de Jesus Cristo. Um caráter pneumático, que se preocupa com a inspiração, a intuição e o discernimento das práticas e virtudes morais em cada pessoa. E, finalmente, um caráter narrativo. Ou seja, para cada cristão, para a comunidade cristã, as normas morais aparecem sempre contextualizadas em narrações. Estas narrações, normalmente, sintetizam, sustentam e conservam uma experiência moral exemplar. Experiência que serve de caminho, paradigma, horizonte, para a reflexão moral. As normas não são extrínsecas ao contexto no qual surgiram. É a partir deste contexto que elas encarnam um caminho de interpretação e solução de um conflito, um desafio, uma tarefa. Isto, normalmente acontece a partir da ponderação e do discernimento de bens. Estas narrativas não são absolutas, mas, vinculadas a um determinado lugar, tempo e circunstância, elas apontam uma busca de solução que é sintetizada depois numa norma. Ora, como é possível hoje para a teologia moral, preocupada com a ação do cristão no mundo, escapar da cadeia em que as normas podem ficar presas, e deixar que as narrativas fundantes ainda continuem a gerar discernimentos, decisões e caminhos éticos de florescimento do humano em nosso tempo?

Portanto, como tentei mostrar, a filosofia de Maclntyre pode fecundar a reflexão dos teólogos em várias direções. Aqui pensei especificamente na questão narrativa. Esta dimensão, tão importante em nossas vidas, não pode ficar de fora da reflexão acerca do lugar da religião em nossas sociedades e da experiência de fé em nossa existência humana no mundo histórico. 


\section{Referências}

GEFFRÉ, C. Como fazer teologia hoje: hermenêutica teológica. São Paulo: Paulinas, 1989.

GESCHÉ, A. Dieu pour penser: Dieu. Paris, Cerf, 1994.

GOPEGUI, J. R. A experiência de Deus e a catequese narrativa. São Paulo: Loyola, 2010. HAUERWAS, S. The virtues of Alasdair Maclntyre. First Things - Journal of religion, culture and public life (p.1-13). October 2007.

HAUERWAS, S. How I think I learned to think theologically. American Catholic Philosophical Quarterly. New York: American Catholic Philosophical, v.88, n.4, p.641658, m.10, 2014.

JOÃO PAULO II. Carta Encíclica Fides et Ratio do Sumo Pontífice João Paulo Il aos bispos da Igreja Católica sobre as relações entre fé e razão. São Paulo: Loyola, 1998.

JUNGEL, E. Paolo e Gesù: alle origini della cristologia. Brescia: Paideia, 1978.

KASEMANN, E. Ensayos exegeticos. Salamanca: Sigueme, 1978.

KEENAN, F. Virtude e Identidade. Concilium. Petropólis, n.2, 285, p.79-89, 2000.

KENNEDY, T. The intelligibility of Moral Tradition in the thought of Alasdair Maclntyre. Studia Moralia. Roma, v.29/2, p. 305-321, 1991.

KIRKHAM, R. Teorias da verdade: uma introdução crítica. São Leopoldo: Unisinos, 2003. MACINTYRE, A. Depois da virtude: um estudo em teoria moral. Bauru: EDUSC, 2001. MACINTYRE, A. The tasks of philosophy. Cambridge: Cambridge University Press, 2006. MACINTYRE, A. Justiça de quem? Qual racionalidade? São Paulo: Loyola, 2008. MACINTYRE, A. God, philosophy, universities: a selective history of the catholic philophical tradition. Lanham: Rowman \& Littlefield, 2009.

MCKEEVER, M. God's justice? Right reason? Justice and rationality in Catholic Social Teaching in the light of Alasdair Maclntyre's conception of traditions of enquiry. Studia Moralia. Roma, v.43/1, p.297-317, 2005. 
MCKEEVER, M. The originality of Alasdair Maclntyre's reading of Aquinas on Justice. Studia Moralia. Roma, v.46/2, p.501-518, 2008.

PALACIO, C. Que significa crer em Jesus Cristo hoje? Preâmbulos para uma fé sensata e responsável. Revista Horizonte. Belo Horizonte, n.1, p.41-54, 1997.

PESCH, O. Teologia das virtudes e virtudes teologais. Concilium. Petropólis, n.3, 211, p.92-112, 1987.

RAD, G. Teologia do antigo testamento: teologia das tradições históricas de Israel. São Paulo: Aste, 1973.

RIBEIRO, E. Uma interpretação das relações entre filosofia e teologia a partir da hermenêutica. Atualidade teológica. Rio de Janeiro, v.15, n. 39, p. 273-296, m.09, 2011.

RIBEIRO, E. Religião, verdade e hermenêutica. Revista Horizontes. Belo Horizonte, v.9, n.21, p. 354-361, abr./jun., 2011a.

RIBEIRO, E. Reconhecimento ético e virtudes. São Paulo: Loyola, 2012.

RIBEIRO, E. Existe um imaginário social secularizado na América Latina? Revista Horizonte. Belo Horizonte, v.11, n.29, p.133-148, jan./mar., 2013.

RIBEIRO JUNIOR, N. O caráter narrativo da normatividade em teologia moral. Perspectiva Teológica. Belo Horizonte, v.35, n.95, p.13-38, jan./abr., 2003.

RICOEUR, P. História e verdade. Rio de Janeiro: Forense, 1968.

RICOEUR, P. A hermenêutica bíblica. São Paulo: Loyola, 2006.

RICOEUR, P. O si mesmo como outro. São Paulo: WMF Martins Fontes, 2014.

TAYLOR, C. As fontes do self: a construção da identidade moderna. São Paulo: Loyola, 1997

Doutor em Filosofia pela Pontifícia Universidade Gregoriana de Roma - Itália Professor do Programa de Pós-Graduação em Filosofia (FAJE) E-mail: eltonvitoriano@gmail.com 